\title{
DESIGN CRIATIVO NO DESENVOLVIMENTO DE ELEMENTOS ARQUITETÔNICOS MODULARES.
}

\section{Julia Beatriz Estevan*; Larissa D. Soares*; Ana Lúcia Nogueira de Camargo Harris}

\section{Resumo}

Este projeto faz parte de um conjunto de pesquisas, principalmente de iniciação científica, vinculadas ao LaFormA FEC [1], voltadas ao desenvolvimento de elementos arquitetônicos, tendo como fio condutor, a geometria da forma aplicada ao design. O objetivo principal foi difundir aos bolsistas a importância da geometria no desenvolvimento consciente da forma nos elementos arquitetônicos, tendo como foco a criatividade em projetos personalizados.

\section{Palavras-chave:}

elemento arquitetônico; geometria dinâmica; modularidade; personalização.

\section{Introdução}

Por meio de atividades com partes teóricas referenciadas e práticas foram abordados os seguintes temas: geometria dinâmica (AT01 e AT02); elementos arquitetônicos e sustentabilidade (AT03), desenvolvimento criativo sistematizado e produção modular (AT04). A atividade final AT05 será a participação das bolsistas como monitoras nas atividades do LaFormA FEC no CAFin 2019.

Figura 1. Exemplo da AT01 - Caleidociclos.
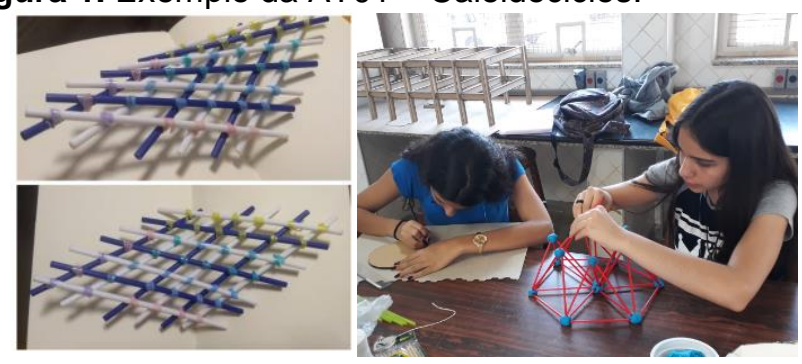

Figura 2. Exemplo da AT02 - introdução à geometria espacial e paraboloide-hiperbólico.

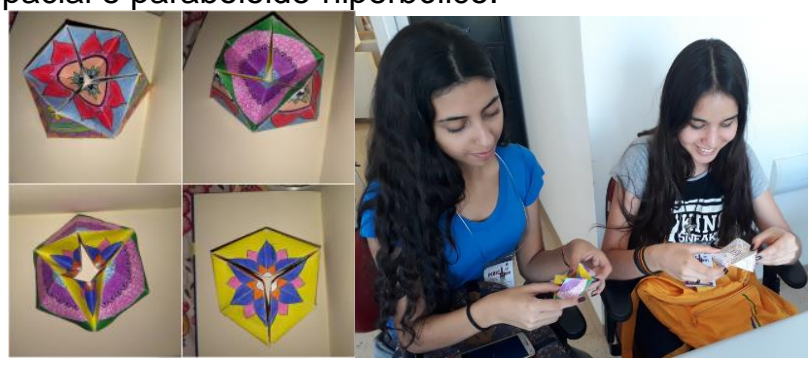

Figura 3. Exemplo da AT03 - monitoria na UPA 2019 hipérbole de uma folha.

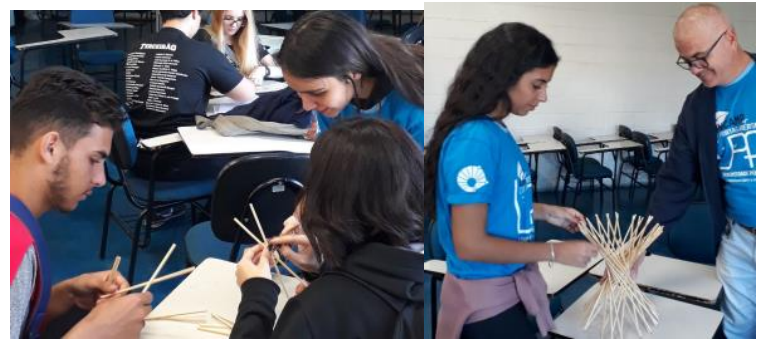

Figura 4. Exemplo da AT04 - monitoria na UPA 2019 hipérbole de uma folha.

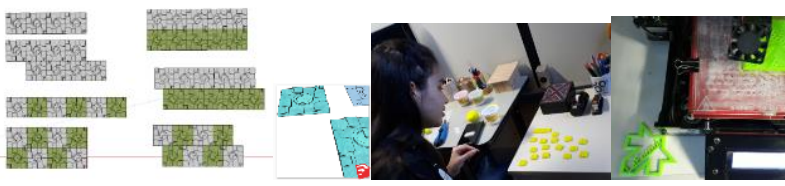

\section{Resultados e Discussão}

Visando enfatizar a importância da Geometria na concepção de elementos arquitetônicos, abordou-se ao longo do período desta pesquisa, diferentes visões relacionadas ao objeto.

O desenvolvimento prático de formas com base na geometria permitiu às bolsistas a compreensão de que é uma área de grande importância e que, se bem utilizada, favorece no desenvolvimento qualitativo dos elementos arquitetônicos, sejam eles fixos ou dinâmicos, modulares ou únicos.

Além disso, a aplicação de uma sistematização da criatividade no desenvolvimento de padrões modulares permitiu a compreensão de que regras geométricas podem auxiliar a fluidez consciente da criatividade no desenvolvimento personalizado do projeto.

\section{Conclusões}

Os projetos realizados foram muito importantes no desenvolvimento da criatividade, trazendo novas possibilidades com materiais pouco utilizados $e$ aperfeiçoando a habilidade de se realizar uma pesquisa de acordo com a necessidade do projeto. Além disso, a execução atividades práticas auxiliou na aprendizagem.

\section{Agradecimentos}

À Unicamp por esta oportunidade permitindo uma vivência universitária. Ao CNPq pelo incentivo à pesquisa no Brasil.

[1]Laboratório de Estudos da Forma Arquitetônica da Faculdade de Engenharia Civil, Arquitetura e Urbanismo da UNICAMP.

LaFormA - www.fec.unicamp.br/ laforma 